\title{
OPEN Author Correction: Comparisons of different indices of low muscle mass in relationship with cardiometabolic disorder
}

\author{
JuYoung Kim (1), Sohee Oh, Hwa Yeon Park, Ji Hye Jun \& Hwa Jung Kim \\ Correction to: Scientific Reports https://doi.org/10.1038/s41598-018-37347-3, published online 24 January 2019 \\ In this Article, the legend of Figure 1 is incorrect: \\ "Selection of study participants" \\ should read: \\ "Comparison of ROCs in metabolic syndrome among different low muscle mass indices in male" \\ Additionally, the legend of Figure 2 is incorrect: \\ "Comparison of ROCs in metabolic syndrome among different low muscle mass indices in male" \\ should read:
}

"Comparison of ROCs in metabolic syndrome among different low muscle mass indices in female"

In addition, the legend of Figure 3 is incorrect:

"Comparison of ROCs in metabolic syndrome among different low muscle mass indices in female"

should read:

"Selection of study participants"

Open Access This article is licensed under a Creative Commons Attribution 4.0 International
License, which permits use, sharing, adaptation, distribution and reproduction in any medium or
format, as long as you give appropriate credit to the original author(s) and the source, provide a link to the Cre-
ative Commons license, and indicate if changes were made. The images or other third party material in this
article are included in the article's Creative Commons license, unless indicated otherwise in a credit line to the
material. If material is not included in the article's Creative Commons license and your intended use is not per-
mitted by statutory regulation or exceeds the permitted use, you will need to obtain permission directly from the
copyright holder. To view a copy of this license, visit http://creativecommons.org/licenses/by/4.0/.

(C) The Author(s) 2020 